\title{
Distributive concerns in the bankruptcy problem with an endogenous estate
}

Citation for published version (APA):

Karagozoglu, E. (2008). Distributive concerns in the bankruptcy problem with an endogenous estate. METEOR, Maastricht University School of Business and Economics. METEOR Research Memorandum No. 032 https://doi.org/10.26481/umamet.2008032

Document status and date:

Published: 01/01/2008

DOI:

10.26481/umamet.2008032

Document Version:

Publisher's PDF, also known as Version of record

\section{Please check the document version of this publication:}

- A submitted manuscript is the version of the article upon submission and before peer-review. There can be important differences between the submitted version and the official published version of record.

People interested in the research are advised to contact the author for the final version of the publication, or visit the DOI to the publisher's website.

- The final author version and the galley proof are versions of the publication after peer review.

- The final published version features the final layout of the paper including the volume, issue and page numbers.

Link to publication

\footnotetext{
General rights rights.

- You may freely distribute the URL identifying the publication in the public portal. please follow below link for the End User Agreement:

www.umlib.nl/taverne-license

Take down policy

If you believe that this document breaches copyright please contact us at:

repository@maastrichtuniversity.nl

providing details and we will investigate your claim.
}

Copyright and moral rights for the publications made accessible in the public portal are retained by the authors and/or other copyright owners and it is a condition of accessing publications that users recognise and abide by the legal requirements associated with these

- Users may download and print one copy of any publication from the public portal for the purpose of private study or research.

- You may not further distribute the material or use it for any profit-making activity or commercial gain

If the publication is distributed under the terms of Article $25 \mathrm{fa}$ of the Dutch Copyright Act, indicated by the "Taverne" license above, 


\section{Emin Karagozoglu}

Distributive Concerns in the Bankruptcy Problem with an Endogenous Estate

$\mathrm{RM} / 08 / 032$

JEL code: C72, D63, D71

\section{METE@R}

Maastricht research school of Economics of TEchnology and ORganizations

Universiteit Maastricht

Faculty of Economics and Business Administration

P.O. Box 616

NL - 6200 MD Maastricht

phone : ++31433883830

fax : ++31433884873 


\title{
Distributive Concerns in the Bankruptcy Problem with an Endogenous Estate*
}

\author{
Emin Karagozoglu ${ }^{\dagger}$ \\ Maastricht University, Department of Economics \\ September 13, 2008
}

\begin{abstract}
We compare certain bankruptcy rules in a bankruptcy model with an endogenous estate on the basis of normative criteria. In particular, five properties related to distributive concerns are analyzed: minimal rights first, securement of initial investments, initial investments first, reasonable lower bounds on awards, and reasonable lower bounds on losses. The proportional rule receives the strongest support from this normative analysis among the rules considered. We also observe that the performance of the proportional rule improves in the family of bankruptcy problems with endogenous estates compared to the general set of bankruptcy problems. Our results complement those in Karagozoglu (2008) and provide a broader perspective to bankruptcy problems with endogenous estates.
\end{abstract}

JEL Codes: C72, D63, D71.

Keywords: Bankruptcy Problems, Normative Analysis, Distributive Concerns, Proportional Rule, Constrained Equal Awards Rule, Constrained Equal Losses Rule.

${ }^{*}$ I would like to thank my advisor, Bettina Klaus, for helpful suggestions and discussions. I am also grateful to Kristof Bosmans and Arno Riedl for their valuable comments. All remaining errors are mine.

${ }^{\dagger}$ Contact Info: Department of Economics, Maastricht University, P.O. Box 616, 6200 MD, Maastricht, The Netherlands. Phone : +31 (0) 433883925 Fax: +31 (0) 4338848 78. Email: E.Karagozoglu@ALGEC.unimaas.nl. 


\section{Introduction}

The bankruptcy problem was first introduced formally by O'Neill (1982). It can simply be described as a situation in which there is a perfectly divisible estate to be allocated to a finite number of agents, whose claims add up to an amount larger than the estate. ${ }^{1}$ Mathematically, a bankruptcy problem can be represented by a finite dimensional claims vector and an estate with a positive value. A bankruptcy rule is a function that associates a division of the estate in every bankruptcy problem. Many real life situations such as distributing a will to inheritants, liquidation of the assets of a bankrupt company, rationing, taxation, and sharing the costs of a public facility can be described using parsimonious bankruptcy models.

There are three different approaches to analyze bankruptcy problems: normative (axiomatic), cooperative and noncooperative game theoretical. ${ }^{2}$ This paper falls into the first category, which aims to compare different rules by their properties. In recent years, a growing number of papers, analyzing the distributive properties of bankruptcy rules have appeared. For instance, Moreno-Ternero \& Villar (2004) provide a characterization of the Talmud rule on the basis of the securement property, which proposes a lower bound on the awards that agents receive. Hougaard \& Østerdal (2005) show that among continuous and order preserving bankruptcy rules, the proportional rule is the only one that preserves inequality in awards and losses. Yeh (2006) provides three characterizations of the constrained equal awards rule based on two "protective properties", i.e., sustainability and exemption. Bosmans \& Lauwers (2006) compare nine well-known bankruptcy rules on the basis of Lorenz domination. Most recently, Thomson (2007) offers criteria to compare bankruptcy rules on the basis of Lorenz ranking.

In this paper, we analyze the distributive properties of three prominent bankruptcy rules in the class of bankruptcy problems with endogenous estates (BPEE). This new class is introduced by Karagozoglu (2008) in which the value of the estate depends on the value of claims, i.e., it is not exogenously given.

The analysis of bankruptcy problems with endogenous estates is important since it has a potential to offer policy implications to managers in companies and policymakers in financial markets. The reason is that many real life bankruptcy situations follow a risky investment made by companies, financial institutions, investors, shareholders and/or stockholders. For instance, a company borrows money to finance a risky investment project. The return rate that the company promises to lenders (e.g., investors, shareholders, or stockholders) determines lenders' claims. The realized return rate on total investment determines the estate that can be allocated to lenders. Hence, the estate is not independent from claims and is endogenously determined by lenders' investment decisions. In this class of bankruptcy problems, bankruptcy rules'

\footnotetext{
${ }^{1}$ This corresponds to Chapter 7 bankruptcy in the US bankruptcy law.

${ }^{2}$ For extensive surveys of the literature, the reader is referred to Moulin (2002) and Thomson $(2003 ; 2006)$.
} 
normative performances might differ from their performances in the general class of bankruptcy problems. Therefore, using the results obtained in the general class of bankruptcy problems might lead to wrong policy advises in this class of bankruptcy problems.

Due to its empirical appeal and importance for policymaking as mentioned above, it is interesting to see how bankruptcy rules perform on the basis of distributive properties in the class of bankruptcy problems with endogenous estates. In this paper, we focus on three well-known bankruptcy rules: the proportional rule, the constrained equal awards rule and the constrained equal losses rule. ${ }^{3}$ In particular, we look at five distributive properties: minimal rights first, securement of initial investments, initial investments first, reasonable lower bounds on awards, and reasonable lower bounds on losses.

Our results show that the proportional rule receives the strongest support from this normative analysis among the rules considered. In particular, it satisfies securement of initial investments, initial investments first (although it still does not satisfy minimal rights first), and reasonable lower bounds on awards in the class of bankruptcy problems with endogenous estates. Moreover, it also satisfies reasonable lower bounds on losses under a condition, which is not very restrictive from an empirical point of view. All in all, we observe that the proportional rule becomes more appealing from a normative perspective in the class of bankruptcy problems with endogenous estates compared to the general class of bankruptcy problems. It satisfies some properties in bankruptcy problems with endogenous estates (e.g., reasonable lower bounds on awards and reasonable lower bounds on losses), which it does not satisfy in the general class of bankruptcy problems. This improvement is mainly due to the interdependence of claims and the estate (i.e., endogenous estate formation). In the general class of bankruptcy problems, the estate can take any nonnegative value. However, in the class of bankruptcy problems with endogenous estates, given the claims vector, there is only one value, which the estate can take. As a result, certain values of the estate for which the proportional rule does not satisfy certain properties are eliminated in this class of bankruptcy problems. Moreover, the proportional rule is the only rule among the three rules considered here, which satisfies two new properties introduced in the context of endogenous estate formation i.e., securement of initial investments and initial investments first.

This paper contributes to the literature on bankruptcy problems and the proportional rule in fair division problems. Its contribution to the normative literature on bankruptcy problems is due to the analysis conducted in an empirically appealing class of bankruptcy problems (i.e., bankruptcy problems with endogenous estates), which might produce policy implications for lawmakers, companies and investor associations. In particular, in a liberal bankruptcy regime that enables companies and investors to write their own bankruptcy procedures (see Hart, 2000), both parties

\footnotetext{
${ }^{3}$ In Section 4, we provide results on the Talmud rule, Piniles rule and the constrained egalitarian rule, as well.
} 
can gain from the analysis conducted in this paper. On the other hand, it also contributes to the literature on fair division problems with its main message supporting the proportional rule. Within this literature, our paper is comparably much more related to the equity theory of Selten (1978) and the accountability principle of Konow (2000). The equity theory emphasizes the relative value of inputs and outputs. Since changes in the value of the estate does not affect this value, equity theory favors the use of the proportional solution in our context. Similarly, the accountability principle implies that people should be held responsible for losses in proportion to their initial inputs. The equity theory and the accountability principle are very relevant in our context since inputs (initial investments) and the output (estate) can be clearly identified. Both of these normative arguments support the proportional rule in bankruptcy problems with endogenous estates. The results of our analysis strengthens these arguments with different normative justifications (i.e., on the basis of distributive properties).

The structure of the paper is as follows: In Section 2, we introduce the model of bankruptcy with an endogenous estate and the rules employed in this paper. In Section 3 and its subsections, we conduct a normative analysis on the model presented in Section 2. Section 4 discusses certain extensions and real-life applications. Section 5 concludes with final remarks.

\section{Bankruptcy Problem with an Endogenous Es- tate}

Consider an economy in which a finite set $N=\{1,2, \ldots, n\}$ of agents has invested in a venture capital company with a risky business project, which promised them a return rate of $0<r \leq 1$. The amount agent $i$ invested in the company is denoted, for all $i \in N$, as $w_{i} \geq 0$. Without loss of generality, assume that $w_{1} \leq w_{2} \leq \ldots \leq w_{n}$. Note that $(1+r) w_{i}$ constitutes agent $i$ 's claim. The risky business project failed and could only bring a return rate of $r_{f}$ such that $0 \leq r_{f}<r \leq 1$ in which case not all agents' claims can be honored. ${ }^{4}$ Since the project could only bring a return rate of $r_{f}$, the value of the estate to be divided among the agents is given by $E=\left(1+r_{f}\right) \sum_{i \in N} w_{i}$. Therefore, the sum of claims, $\sum_{i \in N} c_{i}=(1+r) \sum_{i \in N} w_{i}$, is greater than the estate, $E=\left(1+r_{f}\right) \sum_{i \in N} w_{i}$. As the reader might notice, the endogeneity of the estate stems from the fact that the sum of agents' initial investments determine the size of the estate, given $r_{f}$. Below, we provide the definition of bankruptcy problems with

\footnotetext{
${ }^{4}$ As far as our parameter assumptions are concerned: Thomson Venture Economics VentureXpert Database shows that between 1969 and 2003, there were negative average annual returns only in four years and an average annual return more than $100 \%$ prevails only in one year. These figures, at least partially, support our assumptions on $r$ (i.e., $r \leq 1$ ) and $r_{f}$ (i.e., $r_{f} \geq 0$ ). A justification for the assumption, $r>0$, is that people would not be willing to invest in a risky business, which offers them 0 return even in the case of success.
} 
endogenous estates.

Definition 1 (BPEE) A bankruptcy problem with an endogenous estate is a pair $(C, E) \in \mathbb{R}_{+}^{N} \times \mathbb{R}_{+}$, where $C$ is a claims vector with entries $c_{i}=(1+r) w_{i}$ for all $i \in N$ and $E=\left(1+r_{f}\right) \sum_{i \in N} w_{i}$ is the estate. The class of bankruptcy problems with endogenous estates is denoted by $\widetilde{\mathcal{B}}$.

Recall that, in the general class of bankruptcy problems there is no relationship between the claims and the estate. The estate can take any nonnegative value independent of the claims. From this point onwards, the analysis will focus on the class of bankruptcy problems with an endogenous estate, unless otherwise stated. The general class of bankruptcy problems is denoted by $\mathcal{B}$ throughout the paper.

A bankruptcy rule is a mechanism that allocates the estate to agents given any bankruptcy problem. Formally, a bankruptcy rule $F$ is a function mapping each bankruptcy problem $(C, E) \in \widetilde{\mathcal{B}}$ into $\mathbb{R}_{+}^{n}$ such that for all $i \in N, F_{i}(C, E) \in\left[0, c_{i}\right]$ and $\sum_{i \in N} F_{i}(C, E)=E$. Below, we define the bankruptcy rules we analyze in this paper.

The proportional rule dates back to Aristotle who considers it equivalent to justice. The proportional rule allocates the estate proportionally with respect to claims.

Definition 2 (Proportional Rule) For all $(C, E) \in \widetilde{\mathcal{B}}, P(C, E) \equiv \lambda_{p} C$, where $\lambda_{p}$ is given by $\lambda_{p}=\left(E / \sum_{i \in N} c_{i}\right)=\left(1+r_{f}\right) /(1+r)$.

The constrained equal awards rule allocates the estate as equal as possible taking claims as upper bounds. Agents with smaller claims receive more under the constrained equal awards rule than what they would receive under the proportional rule. Hence, loosely speaking, this rule favors agents with smaller claims.

Definition 3 (Constrained Equal Awards Rule) For all $(C, E) \in \widetilde{\mathcal{B}}$, and all $j \in N, C E A_{j}(C, E) \equiv \min \left\{c_{j}, \lambda_{\text {cea }}\right\}$, where $\lambda_{\text {cea }}$ solves $\sum_{i \in N} \min \left\{c_{i}, \lambda_{\text {cea }}\right\}=E$.

The constrained equal losses rule allocates the shortage of the estate (i.e., the total loss due to bankruptcy) in an equal way (shares bounded below by zero). Agents with bigger claims receive more under the constrained equal losses rule than what they would receive under the proportional rule. Hence, loosely speaking, this rule favors agents with bigger claims.

Definition 4 (Constrained Equal Losses Rule) For all $(C, E) \in \widetilde{\mathcal{B}}$, and all $j \in$ $N, C E L_{j}(C, E) \equiv \max \left\{0, c_{j}-\lambda_{\text {cel }}\right\}$, where $\lambda_{\text {cel }}$ solves $\sum_{i \in N} \max \left\{0, c_{i}-\lambda_{\text {cel }}\right\}=E$. 


\section{Normative Analysis}

We proceed with the normative analysis of the proportional rule, the constrained equal awards rule and the constrained equal losses rule on the basis of distributive characteristics they possess. In particular, we consider five distributive properties which are: minimal rights first, securement of initial investments, initial investments first, reasonable lower bounds on awards, and reasonable lower bounds losses.

\subsection{Minimal Rights First}

In bankruptcy problems, one can argue that each agent should be entitled to a certain positive amount (which might be different across agents). Social conventions, common sense entitlements, customs, or rules and regulations are some factors supporting this policy concern. These amounts that should be granted to agents are sometimes called minimal rights in the bankruptcy literature. The minimal rights property is introduced by Curiel, Maschler and Tijs (1987). The minimal right of agent $i$ is equal to the amount left after honoring all other agents' claims if this amount is nonnegative and equal to 0 if this amount is negative. Intuitively, agent $i$ 's minimum right is that part of the estate, which is not contested by other agents.

Definition 5 (Minimal Rights) The minimal right of agent $i \in N$ is $m_{i}(C, E) \equiv$ $\max \left\{0, E-\sum_{j \neq i} c_{j}\right\}$.

The minimal rights first property refers to the idea of first granting agents' their minimal rights and then allocating the remaining estate to truncated claims. Based on minimal rights, the minimal rights first property was also introduced by Curiel, Maschler, \& Tijs (1987). A bankruptcy rule $F$ satisfies minimal rights first, if the one-step allocation obtained by applying $F$ is identical to the two-step allocation that involves $F$ in the second step. Below, we give the formal definition of the property. In the definition, $F(C, E)$ refers to the payoff vector under $F$ and $m(C, E)$ refers to the minimal rights vector.

Definition 6 (Minimal Rights First) For all $(C, E) \in \widetilde{\mathcal{B}}$, rule $F$ respects minimal rights first, if

$$
F(C, E)=m(C, E)+F\left(C-m(C, E), E-\sum_{i \in N} m_{i}(C, E)\right) .
$$

The following proposition shows that the constrained equal losses rule satisfies the minimal rights first property in $\widetilde{\mathcal{B}}$, as it satisfies this property in $\mathcal{B}$. Curiel Maschler, \& Tijs (1987) show that the proportional rule and the constrained equal awards rule do not satisfy the property in $\mathcal{B}$. The following proposition shows that the proportional rule and the constrained equal awards rule violate this property in $\widetilde{\mathcal{B}}$, as well. 
Proposition 1 Let $(C, E) \in \widetilde{\mathcal{B}}$. Then, $C E L$ is the only rule among $P, C E A$, and $C E L$ that respects minimal rights first.

Proof. (CEL) Note that $\widetilde{\mathcal{B}} \varsubsetneqq \mathcal{B}$. $C E L$ satisfies the minimal rights first property in $\mathcal{B}$ (see Thomson, 2003). Hence, $C E L$ satisfies the minimal rights first property in $\widetilde{\mathcal{B}}$, as well.

To prove that neither $P$ nor $C E A$ satisfies the property, it is enough to find one counter example. Pick $n=2, w_{1}=10, w_{2}=100, r=0.8$ and $r_{f}=0.2$. This set of parameters are employed for both $P$ and $C E A$, below.

(P) The minimal rights of two agents are

$$
\begin{aligned}
& m_{1}(C, E)=\max \{0,(1+0.2)(110)-(1+0.8)(100)\}=0, \text { and } \\
& m_{2}(C, E)=\max \{0,(1+0.2)(110)-(1+0.8)(10)\}=114 .
\end{aligned}
$$

In the one-step procedure, $P_{2}((18,180), 132)=120$, whereas in the two-step procedure,

$$
m_{2}((18,180), 132)+P_{2}((18,66), 18)=114+14.14=128.14 .
$$

Hence, $P$ does not satisfy the minimal rights first property in $\widetilde{\mathcal{B}}$.

(CEA) In the one-step procedure, $C E A_{2}(C, E)=114$, whereas in the two-step procedure,

$$
m_{2}((18,180), 132)+C E A_{2}((18,66), 18)=114+9=123 .
$$

Hence, $C E A$ does not satisfy the minimal rights first property in $\widetilde{\mathcal{B}}$.

These results in $\widetilde{\mathcal{B}}$ may not be very interesting per-se since there is no difference between the results in $\mathcal{B}$ and $\widetilde{\mathcal{B}}$. However, they open a venue for two new distributive properties we introduce in the following subsection.

\subsection{Securement of Initial Investments and Initial Investments First}

As it can be noticed in the definition of minimal rights, they are determined by making use of the claims vector and the value of the estate. The normative idea behind the property is first allocating the part of the estate, which is uncontested. Loosely speaking, this definition of minimal rights favors agents with bigger claims. Finding reasonable minimal rights is a normative issue in most cases. Fortunately, in the bankruptcy problems with endogenous estates, we have a natural candidate: one might consider that agents' initial investments (i.e., $w_{i}$ ) constitute their "minimal rights" to be honored first. Indeed, this is valid in certain real life instances (e.g., a bank paying depositors' money back in case of bankruptcy). Accordingly, for all bankruptcy problems with endogenous estates, for all $i \in N$, we take $w_{i}$ as a "minimal right" of agent $i$. Below, we formulate the securement of initial investments property. 
Definition 7 (Securement of Initial Investments) For all $(C, E) \in \widetilde{\mathcal{B}}$, rule $F$ respects securement of initial investments, if for all $i \in N, F_{i}(C, E) \geq w_{i}$.

The following proposition shows that the proportional rule has an advantage over the other rules as far as this property is concerned.

Proposition 2 Let $(C, E) \in \widetilde{\mathcal{B}}$. Then, $P$ is the only rule among $P, C E A$ and $C E L$ that respects securement of initial investments.

Proof. (P) Since $P$ pays $\left(1+r_{f}\right) w_{j}$ to each agent $j \in N$ independent of $n, P$ respects securement of initial investments, which are $w_{i}$ under the assumption that $r_{f} \geq 0$.

To prove that neither $C E A$ nor $C E L$ satisfies the securement of initial investments property, one counter example suffices. Pick $n=2, w_{1}=10, w_{2}=100, r=0.8$, and $r_{f}=0.1$. This set of parameters are employed for both $C E A$ and $C E L$, below.

(CEA) $C E A_{2}((18,180), 121)=121 / 2<100=w_{2}$. Hence, $C E A$ does not satisfy securement of initial investments.

(CEL) $C E L_{1}((18,180), 121)=0<10=w_{1}$. Hence, $C E L$ does not respect securement of initial investments.

One might wonder how these three rules perform under the new definition of "minimal rights" as far as the minimal rights first property is concerned. Below, we define the initial investments first property, which is based on the minimal rights first property. The only difference is that the initial investments first property uses $w_{i}$ for all $i \in N$ as minimal rights. $W$ refers to the initial investments vector in the definition below.

Definition 8 (Initial Investments First) For all $(C, E) \in \widetilde{\mathcal{B}}$, rule $F$ respects initial investments first, if

$$
F(C, E)=W+F\left(C-W, E-\sum_{i \in N} w_{i}\right) .
$$

The following proposition shows that the proportional rule satisfies the initial investments first property in $\widetilde{\mathcal{B}}$, whereas others do not.

Proposition 3 Let $(C, E) \in \widetilde{\mathcal{B}}$. Then, $P$ is the only rule among $P, C E A$ and $C E L$ that respects initial investments first.

Proof. (P) We know that $P(C, E)=\left(\left(1+r_{f}\right) w_{1},\left(1+r_{f}\right) w_{2}, \ldots,\left(1+r_{f}\right) w_{n}\right)$. The bankruptcy problem in the second step of the two-step procedure can be written as $\left(\left(r w_{1}, r w_{2}, \ldots, r w_{n}\right), r_{f} \sum_{i \in N} w_{i}\right)$. Hence, $P\left(\left(r w_{1}, r w_{2}, \ldots, r w_{n}\right), r_{f} \sum_{i \in N} w_{i}\right)=$ $\left(r_{f} w_{1}, r_{f} w_{2}, \ldots, r_{f} w_{n}\right)$. Therefore,

$$
P(C, E)=W+P\left(C-W, E-\sum_{i \in N} w_{i}\right),
$$


which proves that $P$ satisfies initial investments first.

To prove that neither $C E A$ nor $C E L$ satisfies the initial investments first, one counter example suffices. The set of parameters used in Proposition 2 are used for $C E A$ and $C E L$, below.

(CEA) Recall that, $C E A_{2}((18,180), 121)=121 / 2<20=w_{2}$. The bankruptcy problem in the second step of the two-step procedure can be written as

$$
\left(\left(r w_{1}, r w_{2}\right), r_{f} \sum_{i=1}^{2} w_{i}\right)=((8,80), 11) .
$$

Hence, $C E A_{2}((8,80), 11)=11 / 2$. But,

$$
\frac{121}{2}=C E A_{2}((18,180), 121) \neq w_{2}+C E A_{2}((8,80), 11)=\frac{211}{2},
$$

which proves that $C E A$ does not satisfy initial investments first.

(CEL) Recall that, $C E L_{1}((18,180), 121)=0<10=w_{1}$. The bankruptcy problem in the second step of the two-step procedure can be written as

$$
\left(\left(r w_{1}, r w_{2}\right), r_{f} \sum_{i=1}^{2} w_{i}\right)=((8,80), 11) .
$$

Hence, $C E L_{1}((8,80), 11)=0$. But,

$$
0=C E L_{1}((18,180), 121) \neq w_{1}+C E L_{1}((8,80), 11)=10,
$$

which proves that $C E L$ does not satisfy initial investments first.

The results in Propositions 2 and 3 show that securement of initial investments and initial investments first also support the widespread use of the proportional rule.

\subsection{Reasonable Lower Bounds on Awards}

Another property capturing a certain distributive aspect is reasonable lower bounds on awards, which is introduced by Moreno-Ternero \& Villar (2004). The reasonable lower bound on awards property appears in Moreno-Ternero \& Villar (2004) as securement, in Thomson (2006) as secured lower bound and in Bosmans \& Lawwers (2007) with the name used here. This property ensures that any agent with a claim less than or equal to the value of the estate receives at least one $n^{\text {th }}$ of his claim independently of others' claims, where $n$ is the number of agents involved in the bankruptcy problem. Below, we provide the formal definition of the property.

Definition 9 (Reasonable Lower Bounds on Awards) For all $(C, E) \in \widetilde{\mathcal{B}}$, rule $F$ respects reasonable lower bounds on awards if for all $j \in N$,

$$
F_{j}(C, E) \geq\left(\frac{1}{n}\right) \min \left\{c_{j}, E\right\}
$$


Moreno-Ternero \& Villar (2004) show that the proportional rule and the constrained equal losses rule do not satisfy the reasonable lower bounds on awards property in $\mathcal{B}$ (see Propositions 1 and 3 ). The following proposition shows that there is an improvement for the proportional rule in $\widetilde{\mathcal{B}}$, but not for the constrained equal losses rule. More precisely, the proportional rule satisfies the reasonable lower bounds on awards property in $\widetilde{\mathcal{B}}$. Obviously, the constrained equal awards rule continues to satisfy the property.

Proposition 4 Let $(C, E) \in \widetilde{\mathcal{B}}$. Then, $C E A$ and $P$ satisfy reasonable lower bounds on awards, but $C E L$ does not.

Proof. (CEA) Note that $\widetilde{\mathcal{B}} \varsubsetneqq \mathcal{B}$. $C E A$ satisfies reasonable lower bounds on awards in $\mathcal{B}$ (see Moreno-Ternero \& Villar, 2004). Hence, $C E A$ satisfies reasonable lower bounds on awards in $\widetilde{\mathcal{B}}$.

(P) To show that $P$ satisfies this property, we look at two subcases: (i) $n=1$ and (ii) $n \geq 2$.

(i) If $n=1$, since $c_{j}=(1+r) w_{j}>\left(1+r_{f}\right) w_{j}=E, \min \left\{c_{j}, E\right\}=E$. Then, since $\left(1+r_{f}\right) w_{j} \geq E=\left(1+r_{f}\right) w_{j}, P$ trivially satisfies the reasonable lower bounds on awards for $n=1$.

(ii) If $n \geq 2$, then we make use of the fact that $P$ satisfies securement of initial investments. Since $P$ satisfies securement of initial investments, this implies for all $j \in N, P_{j}(C, E) \geq w_{j}$. But since $n \geq 2$ and $r \leq 1, w_{j} \geq(1 / n) \min \left\{c_{j}, E\right\}$. Hence, $P$ satisfies the reasonable lower bounds on awards for $n \geq 2$.

(CEL) To prove that $C E L$ does not satisfy reasonable lower bounds on awards, one counter example suffices. Pick $n=2, w_{1}=10, w_{2}=100, r=0.8$ and $r_{f}=0.1$. $C E L_{1}((18,180), 121)=0<(1 / 2) \min \{18,121\}$. Therefore, $C E L$ does not satisfy reasonable lower bounds on awards.

The reason for the fact that the proportional rule does not satisfy reasonable lower bounds on awards in $\mathcal{B}$ but satisfies it in $\widetilde{\mathcal{B}}$ is the endogeneity of the estate in the latter class of problems. In $\widetilde{\mathcal{B}}$, given the claims vector, the value of the estate is determined. Accordingly, there is no path of awards, but just a single vector of awards. This rules out some values of the estate, for which the proportional rule violates reasonable lower bounds on awards.

\subsection{Reasonable Lower Bounds on Losses}

This property is also introduced by Moreno-Ternero \& Villar (2004) and similar to the reasonable lower bounds on awards property, only with the difference that it imposes lower bounds on losses. It ensures that any agent with a claim less than or equal to the total loss loses at least one $n^{t h}$ of his claim independently of others' claims, where $n$ is the number of agents involved in the bankruptcy problem. Hence, it is 
the dual of the reasonable lower bounds on awards property. In fact, it appears in Moreno-Ternero \& Villar (2004) as securement ${ }^{*}$ to denote the duality between two properties. Below, we provide the formal definition of the property.

Definition 10 (Reasonable Lower Bounds on Losses) For all $(C, E) \in \widetilde{\mathcal{B}}$, rule $F$ respects reasonable lower bounds on losses if for all $j \in N$,

$$
F_{j}(C, E) \leq c_{j}-\left(\frac{1}{n}\right) \min \left\{c_{j}, \sum_{i \in N} c_{i}-E\right\} .
$$

Moreno-Ternero \& Villar (2004) show that the proportional rule and the constrained equal awards rule do not satisfy the minimal rights first property in $\mathcal{B}$ (see Propositions 1 and 2). The following proposition shows that the proportional rule satisfies reasonable lower bounds on losses under a mild condition in $\widetilde{\mathcal{B}}$, but the constrained equal awards rule does not. Obviously, the constrained equal losses rule continues to satisfy the property.

Proposition 5 Let $(C, E) \in \widetilde{\mathcal{B}}$. Then, $C E L$ satisfies reasonable lower bounds on losses. Moreover, under the assumption $1 / n \leq\left(r-r_{f}\right) /(1+r)$, $P$ satisfies reasonable lower bounds on losses but CEA does not.

The assumption $1 / n \leq\left(r-r_{f}\right) /(1+r)$ guarantees that given the number of agents, the difference between the sum of claims and the estate is sufficiently large (for all agents to lose a certain amount). Moreover, as the number of agents increases, the condition becomes less restrictive. In particular, it is asymptotically non-binding since as $n$ approaches $\infty$, the left-hand side of the inequality approaches 0 . Hence, the assumption is easier to justify in bankruptcy problems that involve large number of agents. Loosely speaking, this assumption fits in our venture capital company setup.

Proof. (CEL) Note that $\widetilde{\mathcal{B}} \varsubsetneqq \mathcal{B}$. $C E L$ satisfies reasonable lower bounds on losses in $\mathcal{B}$ (see Moreno-Ternero \& Villar, 2004; Thomson, 2006). Hence, CEL satisfies reasonable lower bounds on losses in $\widetilde{\mathcal{B}}$.

(P) First, we show that $P$ satisfies reasonable lower bounds on losses. To show that, we look at two subcases: (i) $n=1$ and (ii) $n \geq 2$.

(i) If $n=1$, since $c_{j}=(1+r) w_{j}>\left(r-r_{f}\right) w_{j}=c_{j}-E, \min \left\{c_{j}, c_{j}-E\right\}=\left(r-r_{f}\right) w_{j}$. Then, since $\left(r-r_{f}\right) \leq\left(r-r_{f}\right), P$ trivially satisfies the property.

(ii) If $n \geq 2$, then we have two possibilities: $\min \left\{c_{j}, \sum_{i \in N} c_{i}-E\right\}$ is equal to $c_{j}$ or $\sum_{i \in N} c_{i}-E$. Assume that $\min \left\{c_{j}, \sum_{i \in N} c_{i}-E\right\}=c_{j}$. This implies that $(1+r) w_{j} \leq\left(r-r_{f}\right) \sum_{i \in N} w_{i}$. Hence, the right hand side of (1) can be written as $((n-1) / n)(1+r) w_{j}$. By our assumption, we know that

$$
\frac{1}{n} \leq \frac{r-r_{f}}{1+r}
$$


This implies

$$
(1+r) w_{j} \leq((n-1) / n)(1+r) w_{j}
$$

since by simplifying (3), we get (2).

If $\min \left\{c_{j}, \sum_{i \in N} c_{i}-E\right\}=\sum_{i \in N} c_{i}-E$, the result is still valid since it is shown to be valid for $c_{j} \geq \sum_{i \in N} c_{i}-E$. Hence, $P$ satisfies reasonable lower bounds on losses.

Now, we show that $C E A$ does not satisfy this property. To show that one counter example is sufficient.

(CEA) Pick $n=2, w_{1}=10, w_{2}=100, r=1$, and $r_{f}=0$. Note that these parameters satisfy $(2) . C E A_{1}((20,200), 110)=20$. Thus, $C E A_{1}((20,200), 110)=$ $20>10=20-(1 / 2) \min \{20,110\}$. Hence, the result follows.

It is, again, apparent that the reason of deviation from the results in $\mathcal{B}$ is that the lower bound of each agent's loss indirectly depends on others' claims in $\widetilde{\mathcal{B}}$. That's also why we need a condition for the proportional rule to satisfy the reasonable lower bounds on losses. Note that $1 / n \leq\left(r-r_{f}\right) /(1+r)$ is both a necessary and sufficient condition.

\section{Discussion}

Sequential Priority Rules: Sequential priority rules are frequently employed in the liquidation processes of companies. This ranking mechanism dates back to early Germanic systems and variant of it is used in almost all modern commercial societies today (see Knight, 1992). Nowadays, priority classes are defined on the basis of seniority (e.g., founding stockholders or new stockholders), status of creditors (e.g., stockholder or bondholder) or status of claims (e.g., secured or unsecured) etc. The American bankruptcy law is a frequently quoted example in which priority classes are federal government (taxes), trustees (administrative expenses of the trustee) and two kinds of creditors (secured and unsecured claims). Moulin (2000) characterizes sequential priority rules with axioms such as consistency, composition up and composition down. As the reader might notice, the distributive properties employed in this paper are based on claim levels. Since priorities in sequential priority rules are exogenous and based on criteria different than sizes of the claims, this class of rules do not satisfy any of the properties we employ here.

In real-life bankruptcy problems, policymakers have certain distributive concerns, which are not solely based on the value of claims. It is apparent that the sequential priority rules are used to take care of such distributive concerns. On the other hand, the proportional rule is shown to satisfy desirable distributive properties and is closely associated with justice since Aristotle. At this point, it is worth mentioning that sequential priority rules employ proportional division within each priority class in practice. This fact is, again, in line with our findings in favor of the proportional rule and can be interpreted as a compromise between the pure priority mechanism and 
the proportional division and an effort to capture certain distributive properties that are not capture by the priority structure.

Talmud Rule, Piniles Rule, and Constrained Egalitarian Rule: We do not analyze all well-known bankruptcy rules in detail in this paper. For instance, the Talmud rule, the Piniles rule and the constrained egalitarian rule are left out. The major reason for leaving out these rules is the fact that there are no drastic changes in results for these rules from $\mathcal{B}$ to $\widetilde{\mathcal{B}}$ and none of them satisfies the two properties introduced in this paper. ${ }^{5}$ The proportional rule would get a normative support stronger than any other rule even if we included these three rules in our analysis. The table below summarizes the results for these three rules in $\mathcal{B}$ and $\widetilde{\mathcal{B}}$.

\begin{tabular}{||l|c|c|c||}
\hline \hline & $T$ & Pin & $C E$ \\
\hline MRF & $+(+)$ & $-(-)$ & $-(-)$ \\
\hline SII & - & - & - \\
\hline IIF & - & - & - \\
\hline RLOA & $-(+)$ & $+(+)$ & $+(+)$ \\
\hline RLOL & $+(+)$ & $-(-)$ & $-(-)$ \\
\hline \hline
\end{tabular}

Table 1: Properties and Rules in $\widetilde{\mathcal{B}}$ and $\mathcal{B}$.

MRF refers to minimal rights first, SII to securement of initial investments, IIF to the initial investments first, RLOA to reasonable lower bounds on awards, and RLOL to reasonable lower bounds on losses. Signs in parentheses show whether the rules satisfy MRF, RLOA, and RLOL in $\mathcal{B}$ or not.

Other Distributive Properties: This paper does not include all the distributive properties defined in the axiomatic literature. For instance, order preservation (in awards and losses), equal treatment of equals, anonymity, midpoint property and claims truncation invariance are not studied here. The reason for leaving out these properties is the fact that there are no interesting differences between the results in $\mathcal{B}$ and $\widetilde{\mathcal{B}}$. In particular, all three rules studied in this paper satisfy order preservation (both in awards and losses), equal treatment of equals, and anonymity both in $\mathcal{B}$ and $\widetilde{\mathcal{B}}$. The proportional rule satisfies the midpoint property both in $\mathcal{B}$ and $\widetilde{\mathcal{B}}$, whereas the constrained equal awards and the constrained equal losses rules fail to satisfy it in neither class of bankruptcy problems. Claims truncation invariance is not an appealing property in the bankruptcy context we consider (see Thomson, 2006).

\footnotetext{
${ }^{5}$ Note that under our parameter assumptions, the Talmud rule coincides with the constrained equal losses rule in $\widetilde{\mathcal{B}}$. That is why it satisfies RLOA in $\mathcal{B}$, but not in $\widetilde{\mathcal{B}}$.

${ }^{6}$ Proofs of the results summarized in this table are available upon request.
} 


\section{Conclusion}

The results in this paper show that the proportional rule, which is shown to have a noncooperative support in Karagozoglu (2008) also receives a normative support in bankruptcy problems with endogenous estates. The table below summarizes the findings in this paper.

\begin{tabular}{||l|c|c|c||}
\hline \hline & $P$ & $C E A$ & $C E L$ \\
\hline MRF & $-(-)$ & $-(-)$ & $+(+)$ \\
\hline SII & + & - & - \\
\hline IIF & + & - & - \\
\hline RLOA & $+(-)$ & $+(+)$ & $-(-)$ \\
\hline RLOL & $+^{*}(-)$ & $-(-)$ & $+(+)$ \\
\hline \hline
\end{tabular}

Table 2: Properties and Rules in $\widetilde{\mathcal{B}}$ and $\mathcal{B}$.

MRF refers to minimal rights first, SII to securement of initial investments, IIF to the initial investments first, RLOA to reasonable lower bounds on awards, and RLOL to reasonable lower bounds on losses. Signs in parentheses show whether the rules satisfy MRF, RLOA, and RLOL in $\mathcal{B}$ or not. ${ }^{*}$ means that $P$ satisfy the property under a mild assumption.

Minimal Rights First: The minimal rights first property requires the allocation obtained by the one-step application of a rule to be identical to the allocation obtained by first granting agents' their minimal rights and applying the rule afterwards. Minimal rights of agents are nonnegative amounts from the estate left to them uncontested by other agents. We already know that only the constrained equal losses rule satisfy this property among the three rules considered, in $\mathcal{B}$. Our results in this paper show that this does not change in $\widetilde{\mathcal{B}}$.

This leads us to two new properties, which are similar to minimal rights and minimal rights first. Here, we deviate from the previous axiomatic literature and define minimal rights differently in our context. It is intuitive to consider agents' initial investments as their minimal rights in bankruptcy problems with an endogenous estate. It also captures certain reality since, for instance, banks are only responsible for paying agents' initial deposits (i.e., without interest earnings) in case of bankruptcy.

Securement of Initial Investments and Initial Investments First: The securement of initial investments property refers to the idea of granting each agent a certain amount in case of bankruptcy. The proportional rule is the only one among the rules analyzed here satisfying securement of initial investments. Moreover, it is the only rule among the three satisfying the initial investments first property. Hence, if the borrower (or the authority, who is responsible for the allocation of the estate) first wants to give agents their initial investments and then allocate the rest of the estate, this procedure will give the same allocation with the one-step allocation, if he uses the proportional rule. 
Reasonable Lower Bounds on Awards: The reasonable lower bounds on awards property has a similar intuition as securement of initial investments. It requires bankruptcy rules to guarantee a certain payment to each agent depending on the value of their claims, the number of agents and the value of the estate. Hence, instead of a fixed minimal right that is valid for every agent, this property guarantees a lower bound on awards possibly different for each agent. The constrained equal awards rule satisfies the property in $\mathcal{B}$ (see, Moreno-Ternero \& Villar, 2004; Thomson, 2006; and Bosmans \& Lauwers, 2007). Hence, our result on the constrained equal awards rule follows from these general results. What differs from the general results is that the proportional rule satisfies reasonable lower bounds on awards in $\widetilde{\mathcal{B}}$.

Reasonable Lower Bounds on Losses: The reasonable lower bounds on losses property is the dual of reasonable lower bounds on awards. It requires the loss of each agent to be greater than a certain amount, which depends on the agent's claim, the number of agents and the value of the estate. By duality, we know that the constrained equal losses rule satisfies reasonable lower bounds on losses in $\mathcal{B}$. Hence, our result on the constrained equal losses rule follows from this more general result. What differs from the general results is that the proportional rule satisfies reasonable lower bounds on losses in $\widetilde{\mathcal{B}}$ under a mild condition, which relates the number of agents to the total loss due to bankruptcy. This condition is not a very restrictive one if the number of agents involved in the bankruptcy problem is large, which is valid for venture capital companies, for instance.

To conclude, the proportional rule receives a stronger support compared to the constrained equal awards rule and the constrained equal losses rule in the normative analyses we conducted in $\widetilde{\mathcal{B}}$. Results obtained in this paper complement the findings in Karagozoglu (2008) and provide a more complete picture for bankruptcy problems with an endogenous estate. We can deduce that the proportional rule has an advantage over other rules considered in $\widetilde{\mathcal{B}}$, due to its improved performance in satisfying desirable distributive properties as well as the noncooperative support provided for it in Karagozoglu (2008). The difference in the performance of the proportional rule also makes it clear that lawmakers should not rely on results in the general class of bankruptcy problems if the estate formation process is endogenous. Moreover, our results gain a special importance in the light of recent suggestions in favor of a more liberal bankruptcy regime, which would enable companies and investors to write their own bankruptcy procedures (see Hart, 2000). In such a liberal system, these parties would benefit greatly from the knowledge on distributive characteristics of different bankruptcy procedures, some of which is provided in this paper. 


\section{References}

[1] Bosmans, K. \& Lauwers, L. (2007) "Lorenz comparisons of nine rules for the adjudication of conflicting claims", CES Discussion Paper 07.05, Katholieke Universiteit Leuven.

[2] Curiel, I., Maschler, M. \& Tijs, S. H. (1987) "Bankruptcy games", Zeitschrift fur Operations Research, 31, pp. A143 - A159.

[3] Hart, O. (2000) "Different approaches to bankruptcy", NBER Working Paper \# 7921.

[4] Hougaard, J. L. \& Østerdal, L. P. (2005) "Inequality preserving rationing", Economics Letters, 87(3), pp. 355 - 360.

[5] Karagozoglu, E. (2008) "A noncooperative approach to bankruptcy problems with an endogenous estate", Maastricht University, mimeo.

[6] Knight, J. (1992) Institutions and Social Conflict, Cambridge University Press, New York.

[7] Konow, J. (2000) "Fair shares: accountability and cognitive dissonance in allocation decisions", American Economic Review, 90(4), pp. 1072 - 1091.

[8] Moreno-Ternero, J. D. \& Villar, A. (2004) "The Talmud rule and the securement of agent's awards", Mathematical Social Sciences, 47(2), pp. 245 257.

[9] Moulin, H. (2000) "Priority rules and other asymmetric rationing methods", Econometrica, 68(3), pp. 643 - 684.

[10] Moulin, H. (2002) "Axiomatic cost and surplus sharing", in: Arrow K., Sen A., Suzumura K. (eds.) Handbook of Social Choice and Welfare, vol. 1. Elsevier, Amsterdam.

[11] O‘Neill, B. (1982) "A problem of rights arbitration from the Talmud," Mathematical Social Sciences, 2(4), pp. 345 - 371.

[12] Selten, R. (1978) "The equity principle in economic behavior", in Gottinger H.W. \& Leinfellner W. (eds.) Decision Theory and Social Effects. Kluwer, Dordrecht, pp. 289 - 301.

[13] Thomson Venture Economics, Venturexpert Database 2003.

[14] Thomson, W. (2003) "Axiomatic and game-theoretic analysis of bankruptcy and taxation problems: a survey", Mathematical Social Sciences, 45(3), pp. 249 $-297$. 
[15] Thomson, W. (2006) How to Divide When There isn't Enough; From the Talmud to Game Theory, unpublished manuscript.

[16] Thomson, W. (2007) "Lorenz rankings of rules for the adjudication of conflicting claims", Rochester Center for Economic Research Working Paper No: 538.

[17] Yeh, C.H. (2006) "Protective properties and the constrained equal awards rule for claims problems: a note", Social Choice and Welfare, 27(2), pp. 221 - 230. 


\section{Appendix}

Definitions of Rules Mentioned in Section 4:

Definition 11 (Talmud Rule) For all $(C, E) \in \widetilde{\mathcal{B}}$, and all $j \in N$,

$$
T_{j}(C, E) \equiv\left\{\begin{array}{l}
\min \left\{\frac{c_{j}}{2}, \lambda_{t}\right\} \text { if } E \leq \sum_{i \in N} \frac{c_{i}}{2} \\
c_{j}-\min \left\{\frac{c_{j}}{2}, \lambda_{t}\right\} \text { otherwise }
\end{array}\right.
$$

where $\lambda_{t}$ solves $\sum_{i \in N} T_{i}(C, E)=E$.

Definition 12 (Piniles Rule) For all $(C, E) \in \widetilde{\mathcal{B}}$, and all $j \in N$,

$$
\operatorname{Pin}_{j}(C, E) \equiv\left\{\begin{array}{l}
\min \left\{\frac{c_{j}}{2}, \lambda_{\text {pin }}\right\} \text { if } E \leq \sum_{i \in N} \frac{c_{i}}{2} \\
\frac{c_{j}}{2}+\min \left\{\frac{c_{j}}{2}, \lambda_{\text {pin }}\right\} \text { otherwise }
\end{array}\right.
$$

where $\lambda_{\text {pin }}$ solves $\sum_{i \in N} \operatorname{Pin}_{i}(C, E)=E$.

Definition 13 (Constrained Egalitarian Rule) For all $(C, E) \in \widetilde{\mathcal{B}}$, and all $j \in$ $N$,

$$
C E_{j}(C, E) \equiv\left\{\begin{array}{c}
\min \left\{\frac{c_{j}}{2}, \lambda_{c e}\right\} \text { if } E \leq \sum_{i \in N} \frac{c_{i}}{2} \\
\max \left\{\frac{c_{j}}{2}, \min \left\{c_{j}, \lambda_{c e}\right\}\right\} \text { otherwise }
\end{array}\right.
$$

where $\lambda_{\text {ce }}$ solves $\sum_{i \in N} C E_{i}(C, E)=E$.

Definition 14 (Sequential Priority Rule Relative to Order $\sigma$; Moulin, 2000) Assume that $\sigma$ is a complete, transitive and anti-symmetric binary relation on $N$. $\sigma(1)=i$ means "agent $i$ has the highest priority in $N$, " $\sigma(2)=j$ means "agent $j$ has the highest priority in $N^{\prime \prime}$ and so on. Then, for all $(C, E) \in \widetilde{\mathcal{B}}$, and all $i, j \in N$,

$$
\left\{S P R_{j}^{\sigma}(C, E)>0 \text { and } \sigma^{-1}(i)<\sigma^{-1}(j)\right\} \Rightarrow\left\{S P R_{i}^{\sigma}(C, E)=c_{i}\right\}
$$

